Research Article

\title{
Responses of Xilingol Fractional Vegetation Cover to Climate Change and Human Activities
}

\author{
Xiangyang Song $\mathbb{D}^{1},{ }^{1}$ Xiang Chen $\mathbb{D}^{1},{ }^{1}$ Xiaodong Wang $\mathbb{D}^{2},{ }^{2}$ Nitu Wu $\mathbb{D}^{3},{ }^{3}$ Aijun Liu $\mathbb{D},{ }^{2}$ \\ Ritu Su $\mathbb{D}{ }^{2}$ Yong Yang $\mathbb{D}^{2},{ }^{2}$ Shujuan Chang $\mathbb{D}^{2}$, and Zhijun Wei $\mathbb{D}^{1}$ \\ ${ }^{1}$ College of Grassland, Resources and Environment, Inner Mongolia Agricultural University, Hohhot 010011, China \\ ${ }^{2}$ Inner Mongolia Grassland Survey and Design Co., Ltd, Hohhot 010051, China \\ ${ }^{3}$ Grassland Research Institute, Chinese Academy of Agricultural Sciences, Hohhot 010010, China
}

Correspondence should be addressed to Zhijun Wei; nmndwzj@imau.edu.cn

Received 20 October 2021; Revised 3 November 2021; Accepted 5 November 2021; Published 25 November 2021

Academic Editor: Fazli Wahid

Copyright ( 92021 Xiangyang Song et al. This is an open access article distributed under the Creative Commons Attribution License, which permits unrestricted use, distribution, and reproduction in any medium, provided the original work is properly cited.

Based on the MODIS NDVI product data source of Xilingol from 2010 to 2019, we use the pixel dichotomous model to retrieve the vegetation coverage in our study. The spatiotemporal changes of the vegetation cover were analyzed in the model by using the meteorological data from researched sites or the vicinal meteorological stations for evaluating the meteorological influence on the vegetation cover changes. Based on this, an evaluation method was established to estimate the relative influences of the climate changes and anthropogenic activities. The main conclusions are as follows: (1) Fractional vegetation cover in Xilingol was decreased from the northeast to the southwest. (2) The overall trend in Xilingol fractional vegetation cover in the 10 -year period shows a fluctuating increasing trend. (3) An opposite distribution pattern was detected between mean precipitation and mean temperature in the study site. (4) Compared with temperature, annual precipitation has a higher correlation with fractional vegetation cover in the study site and is the main climatic factor that affects vegetation growth in the study site. (5) During the 10-year period in the study site, anthropogenic human activities have slightly greater inhibitory effects on vegetation growth than promoting effects. (6) Climate change is a major factor to accelerate grassland degradation from 2010 to 2019 in vegetation degradation regions. The promotion effect of precipitation on vegetation coverage is obviously higher than the limitation of human activities, which leads to the increase of vegetation coverage in 2010-2019.

\section{Introduction}

Fractional vegetation cover refers to the percentage of vertically projected area of vegetation to the total surface extent per unit area and shows vegetation density and the area used by plants for photosynthesis. Fractional vegetation cover is an integrated quantitative marker that reflects the growth status of surface vegetation and measures the ecological environment [1] and is important foundation data for describing ecological environments. As an important ecological parameter, fractional vegetation cover is often used in studies on vegetation changes, ecological environment, water/soil conservation, and climate [2]. It simultaneously serves as an important marker for field measurement, remote sensing inversion, and model estimation studies in ecology, pratacultural science, and water and soil conservancy. Common methods used for measuring cover are surface observation and remote sensing estimation. Among these methods, remote sensing is widely used due to its rapid acquisition speed, wide coverage area, and its ability to display a large amount of information.

In recent years, the effects of climate change on terrestrial vegetation growth and its mechanisms have become a global research hotspot [3]. Many researchers have employed remote sensing estimation models to examine fractional vegetation covers and their responses to climate change. In a climate model study by Gutman et al. (1998), NOAA AVHRR data was used to propose uniform pixel and equal density model, nondense model, and mixed density model [4]. Hilker et al. studied the relationship between vegetation and climate in the Amazon rainforest in South America and pointed out that extreme climate change has 
significant effects on and is correlated with vegetation cover [5]. Zhao et al. (2011) used NDVI data and corresponding climate data to study the responses of biomes to climate change in northwestern China. These previous studies showed that NDVI changes are highly correlated with precipitation and evapotranspiration during the growth season and not correlated with temperature [6], which is consistent with the study by Peng et al. Peng et al. estimated fractional vegetation cover from MODIS NDVI data in the core region of the Hulunbuir steppe in China and pointed that intense changes in fractional vegetation cover during the greening period and yellowing period have a higher correlation with temperature. During the peak growth season (July to August), intense changes in fractional vegetation cover are mainly associated with precipitation [7]. Yin et al. (2013) found that the ecological responses of vegetation on climate change regulated the species composition and dynamic changes in soil carbon [3]. Wessels et al. (2007) conducted a study and found that NDVI has good consistency with precipitation and temperature by researching the regional dominant plants, particularly during spring and summer [8]. The aforementioned studies examined the precision of different remote sensing data sources in fractional vegetation cover estimation. Some studies examined the effects of meteorological data on changes in cover during different growth periods, while other studies examined the effects of different climatic factors on changes in vegetation cover. However, most studies of the NDVI are mainly focused on the substitute for fractional vegetation cover for correlation analysis with climatic factors, but few studies examine the effect of human activities on fractional vegetation cover, except the joint impact of climate change and human activities.

The Xilingol grassland is a core region in the Eurasian terrestrial grassland, a region that is sensitive to ecological environment changes in the world, and is also a transition belt between the arid regions in northwest China and the wet regions in eastern China [9]. In recent years, human activities and climate change have resulted in degradation of the Xilingol league grassland, decreased productivity, and dysregulated ecosystem function in grasslands, which severely affect the survival and development of local residents and threatens ecological safety in northern China [10]. Therefore, this study was conducted to understand the variation trends of Xilingol fractional vegetation cover and determined the effects of human activities and climate change on cover in Xilingol grassland. Considering the limited water in the semiarid steppe, we hypothesized that (1) climate change affected vegetation coverage from 2010 to 2019 and (2) climatic factors and nonclimatic factors jointly affect changes in fractional vegetation cover.

\section{Data and Methods}

2.1. Overview of the Study Site. The Xilingol League is located in northern China (Figure 1), with a latitude of $43^{\circ} 02^{\prime}-44^{\circ} 52^{\prime}$ $\mathrm{N}$ and a longitude of $115^{\circ} 13^{\prime}-117^{\circ} 06^{\prime} \mathrm{E}$, as well as an altitude of $800-1800 \mathrm{~m}$. The climate is continental arid and semiarid. The annual mean temperature is $1-2^{\circ} \mathrm{C}$ and annual precipitation is 100-350 mm. The Xilingol League consists mostly of plateaus, land cover consists mainly of the geographical units of grassland, and grassland area is $95 \%$ of the total area. The soil type in Xilingol grassland from east to west is chernozemic soil, chestnut soil, and brown calcic soil. Grassland vegetation that is adapted to zonal soils includes temperate meadow grassland, temperate typical grassland, and temperate desert grassland [10]. The representative plants of the temperate meadow grassland are Stipa baicalensis and Leymus chinensis; the representatives plants of the temperate typical grassland are Stipa krylovii and Stipa grandis; and temperate desert grasslands are mainly composed of Stipa klemenzii, Cleistogenes squarrosa, and Stipa glareosa.

\subsection{Data Source and Preprocessing}

2.2.1. Remote Sensing Data. The MOD13Q1 data product (https://ladsweb.modaps.eosdis.nasa.gov/) in the MODIS NDVI imaging data was selected for this study. This product has a temporal resolution of $16 \mathrm{~d}$ and spatial resolution of $250 m \times 250 \mathrm{~m}$, and the time series was 2010-2019. Data during the peak growth period (July to August) every year was selected, including data from two orbits (h25v04 and h26v04). The MODIS Reprojection Tool (MRT) software was used for format conversion, splicing, and cropping of the downloaded data. Maximum value compositing was used to generate the maximum NDVI data during the growth season every year [7].

2.2.2. Surface Measurement Data. The sample plot quadrat method was used for ground sample data. Sample plots representing the region were selected in the study site and covered all grassland types. In every August in 2017-2019, cover was measured and 270 plots were set up every year. Each plot contained three quadrats, and area was $1 m \times 1 \mathrm{~m}$. Every year, 810 cover data points were measured, and the frequency of major plants in the quadrats was recorded. Spatial interpolation was carried out on measured cover data in each sample plot to obtain measured cover raster data that has consistent pixel size and identical projection system as NDVI data.

2.2.3. Meteorological Data. Annual mean temperature and annual precipitation data in Inner Mongolia and its neighboring provinces in 2010-2019 were obtained from the China Meteorological Administration (http://data.cma.cn/) and used as meteorological data. ANUSPLIN local thin-plate smoothing spline interpolation [11] was used for interpolation of annual mean temperature and annual precipitation to ultimately generate meteorological data raster images that have consistent pixel size and identical projection system as NDVI data.

\subsection{Study Methods}

2.3.1. Dimidiate Pixel Model. The dimidiate pixel model was used for inversion of fractional vegetation cover. This model is a simpler model among mixed pixel decomposition models. As the model input parameters are easy to obtain and calculation results are reliable, this model is widely used [12]. Assuming that a pixel is composed of vegetation or bare 


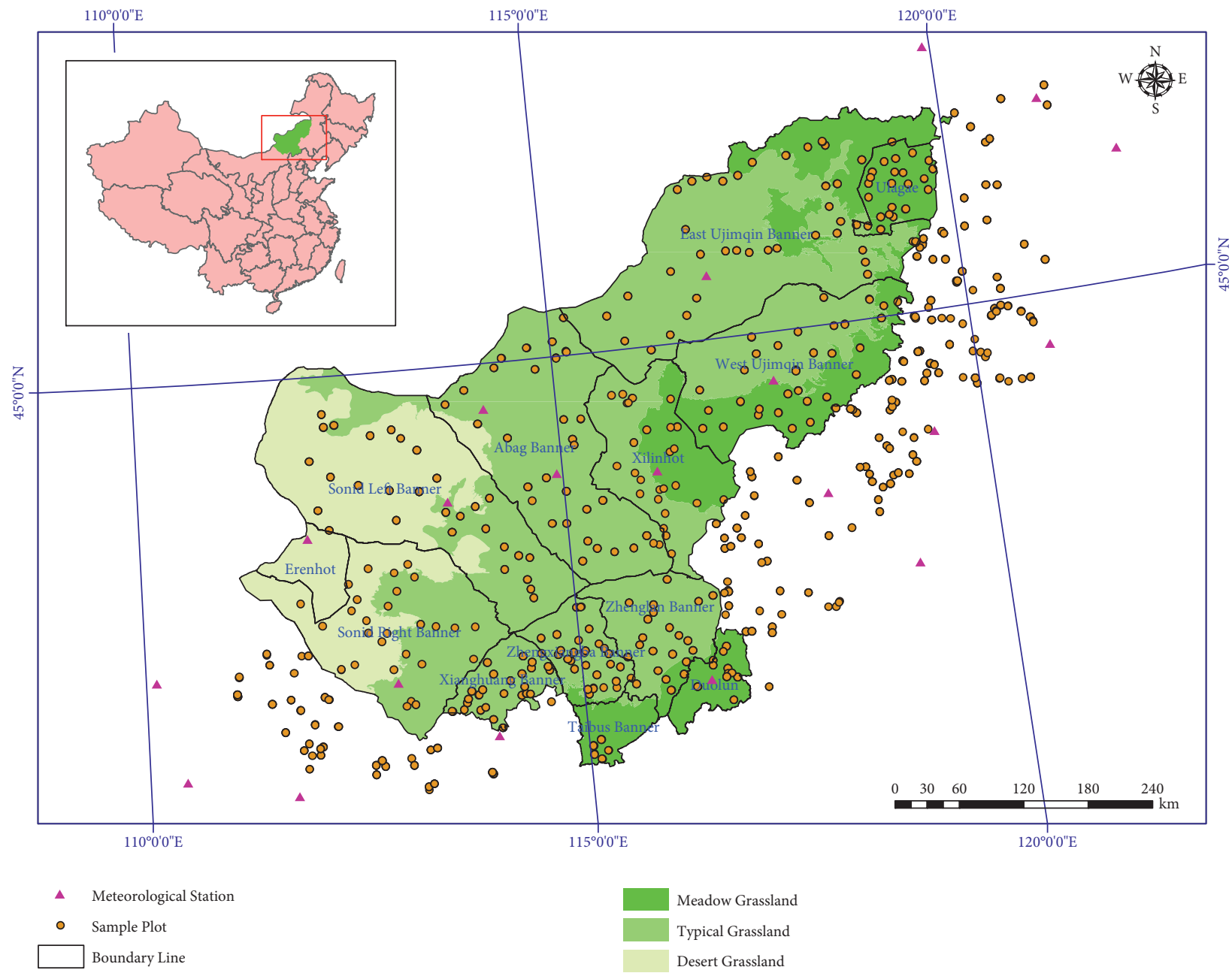

Figure 1: Map of the study site.

soil, pixels that are covered entirely by vegetation and bare soil are recorded as $S_{\text {veg }}$ and $S_{\text {soil }}$, respectively, to obtain the calculation formula for pixel information $S$ :

$$
S=C \times S_{\mathrm{veg}}+(1-C) \times S_{\text {soil }} .
$$

From equation (1), the calculation formula for pixel vegetation cover can be obtained:

$$
C=\frac{\left(S-S_{\text {soil }}\right)}{\left(S_{\text {veg }}-S_{\text {soil }}\right)}
$$

NDVI is an important parameter that reflects vegetation growth status and is expressed as a ratio, which can reduce the effects of errors due to solar angle, cloud shadows, terrain, and instruments [13]. Therefore, NDVI was used as a dimidiate model parameter to estimate fractional vegetation cover to obtain the following equation:

$$
C=\frac{\left(N D V I-N D V I_{\text {soli }}\right)}{\left(N D V I_{\text {veg }}-N D V I_{\text {soli }}\right)}
$$

where $\mathrm{NDVI}_{\text {soil }}$ is the NDVI value of regions that are completely covered by bare soil, and $\mathrm{NDVI}_{\mathrm{veg}}$ is the NDVI value of regions that are completely covered by vegetation.
Determining $\mathrm{NDVI}_{\text {soil }}$ and $\mathrm{NDVI}_{\mathrm{veg}}$ values is critical to the dimidiate pixel model. After repeated comparisons, the NDVI value with a cumulative frequency of $5 \%$ and $95 \%$ was taken to be $\mathrm{NDVI}_{\text {soil }}$ and $\mathrm{NDVI}_{\mathrm{veg}}$, respectively [14]. Finally, the fractional vegetation cover of the study site was calculated. As the selected NDVI is the highest NDVI in the annual growth season and represents the maximum NDVI in the year, the fractional vegetation cover that was ultimately calculated is the annual maximum fractional vegetation cover.

2.3.2. Variation Trend Analysis. Variation trend analysis refers to a method for analyzing continuous increase or reduction of a certain factor during a long period of time. In this study, the following equation [15] was used for dynamic variation trend analysis of highest fractional vegetation cover in grasslands in the study site for 10 years:

$$
\theta_{\text {slope }}=\frac{n \times \sum_{i=1}^{n} i \times C_{i}-\sum_{i=1}^{n} \sum_{i=1}^{n} C_{i}}{n \times \sum_{i=1}^{n} i^{2}-\left(\sum_{i=1}^{n} i\right)^{2}} .
$$

Here, $\theta_{\text {slope }}$ is the slope of the trend, $n$ is the number of years in the monitoring period, and $C_{i}$ is the maximum fractional vegetation cover in the $i$ th year. The correlation between the fractional vegetation cover series and time series (year) was used 
to determine the annual variation trend of fractional vegetation cover. In this study, the $t$-test was used to determine the significance of the variation trend with significance levels of 0.1 and 0.05 . Variation trends were divided into six levels according to the test results: extremely significant decrease $\left(\theta_{\text {slope }}<0\right.$, $P<0.01)$, significant decrease $\left(\theta_{\text {slope }}<0,0.05<P<0.1\right)$, nonsignificant decrease $\left(\theta_{\text {slope }}<0, P>0.1\right)$, extremely significant increase $\left(\theta_{\text {slope }}>0, P<0.05\right)$, significant increase $\left(\theta_{\text {slope }}>0\right.$, $0.05<P<0.1)$, and nonsignificant increase $\left(\theta_{\text {slope }}>0, P>0.1\right)$.

2.3.3. Correlation Analysis. In the system, changes to one factor will inevitably cause changes in other factors. Hence, partial correlation analysis was used to study the interactions between two specific variables. In this study, pixel-based spatial analysis was used to analyze the partial correlation between fractional vegetation cover and temperature and precipitation. First, the simple correlation coefficient was calculated to obtain the partial correlation coefficient. The formula (5) for calculating the correlation coefficient between fractional vegetation cover and temperature or precipitation is as follows:

$$
R_{x y}=\frac{\left[\sum_{i=1}^{n}(x-\bar{x})(y-\bar{y})\right]}{\sqrt{\sum_{i=1}^{n}(x-\bar{x})(y-\bar{y})^{2}}},
$$

where $R_{x y}$ is the correlation coefficient of two variables, $x_{i}$ is the fractional vegetation cover of the ith year, $y_{i}$ is the temperature or precipitation of the $i$ th year, ${ }^{-} x$ is the annual mean fractional vegetation cover, ${ }^{-} y$ is the annual mean temperature or precipitation, and $n$ is the sample size. The greater the absolute value of $R_{x y}$, the closer the relationship between two groups of variables; otherwise, the relationship is weak. Following that, partial correlation analysis was used, in which one variable was controlled and the correlation between the other two variables was analyzed. The calculation formula for the partial correlation relationship between fractional vegetation cover and temperature based on precipitation and the partial correlation relationship between precipitation and fractional vegetation cover based on temperature is as follows (6):

$$
r_{12-3}=\frac{\left[R_{12}-R_{13} \times R_{23}\right]}{\sqrt{\left(1-R_{12}^{2}\right)+\left(1-R_{23}^{2}\right)}} .
$$

where $r_{12-3}$ is the partial correlation coefficient between variables 1 and 2 after fixing variable $3 . R_{12}, R_{13}$, and $R_{23}$ are the correlation coefficients between variables 1 and 2 , variables 1 and 3, and variables 2 and 3, respectively. The correlation between mean fractional vegetation cover and temperature and precipitation was analyzed according to existing fractional vegetation cover, temperature, and precipitation data. The $t$-test was used to examine whether the relationship between two factors is significant and two significance levels (0.1 and 0.05) were used for significance testing.

2.3.4. Residual Analysis. Climatic factors and nonclimatic factors jointly affect changes in fractional vegetation cover. In order to determine which effect is dominant, residual analysis was introduced in this study. Residual analysis was first proposed by Evans and Geerken [16], and the equation is as follows:

$$
\begin{aligned}
C_{\text {pre }} & =a \times T_{\text {mean }}+b \times P_{\text {total }}+c, \\
\varepsilon & =C_{\text {real }}-C_{\text {pre }},
\end{aligned}
$$

where $C_{\text {pre }}$ represents the effects of climatic factors on fractional vegetation cover and is obtained by using the bivariate regression model of temperature and precipitation; $T_{\text {mean }}$ and $P_{\text {total }}$ represent mean temperature and cumulative precipitation at the pixel scale during the growth season, respectively; $a, b$, and $c$ are regression model parameters; $C_{\text {real }}$ is the fractional vegetation cover calculated from the actual model. $\varepsilon$ is the residual and represents the effects of human activities on vegetation. When $\varepsilon>0$, human activities have positive effects on vegetation. When $\varepsilon<0$, human activities have negative effects on vegetation. When $\varepsilon=0$, human activities have no effect on vegetation.

2.3.5. Relative Effect Analysis. In order to determine whether changes in fractional vegetation cover are due to the effects of climate or human activities, we introduced the relative effects theory proposed by Xu [17]. First, residual analysis was used to obtain cover values due to climate change and human activities in every raster pixel. The effects of climate change were measured by the predicted cover value, while the effects of human activities were measured by the cover residual. Following that, trend analysis of predicted cover and cover residual was carried out before combining with the variation trends of actual cover values in 2010-2019 to construct evaluation methods for calculating the relative effects of climate change and human activities in three different scenarios, as shown in Table 1.

\section{Results and Analysis}

3.1. Precision Test. Cover data measured every August in 2017-2019 was used for linear correlation analysis with remote sensing estimated cover data in the same period. Results showed that there is high correlation between estimation results from the NDVI dimidiate pixel model and measured values $(P<0.001)$ and correlation coefficient was 0.7267 (Figure 2). The regression formula was used for refitting and the variation trends for fractional vegetation cover and dimidiate pixel model estimated cover were completely consistent (Figure 3), showing that it is feasible to employ the dimidiate pixel model to estimate fractional vegetation cover in the study site.

\subsection{Spatiotemporal Variation Characteristics of Fractional Vegetation Cover}

3.2.1. Spatial Layout of Mean Cover in Xilingol Grassland in a 10-Year Period. According to the spatial distribution of mean fractional vegetation cover in 2010-2019 (Figure 4), the vegetation coverage is high in the northeast, low in the southwest, and decreasing in the southwest in Xilingol. The mean fractional vegetation cover of the study site in the 10 -year period was $28 \%$; specifically, the value was the highest in the temperate meadow grassland, followed by temperate typical grassland and then temperate desert grassland. The spatial differences were significant. 
TABLE 1: Evaluation methods for the relative effects of climate change and human activities on fractional vegetation cover in various scenarios.

\begin{tabular}{|c|c|c|c|c|c|c|}
\hline $\begin{array}{l}\text { Vegetation } \\
\text { change }\end{array}$ & Scenario & $C_{\text {slope }}$ & $H_{\text {slope }}$ & Relative effects of climate & Relative effect of human & Description \\
\hline \multirow[t]{3}{*}{$\begin{array}{l}\text { Vegetation } \\
\text { improvement } \\
\text { regions }\end{array}$} & Scenario 1 & $>0$ & $>0$ & $\left|\Delta C_{\text {pre }}\right| /\left|\Delta C_{\text {pre }}\right|+\left|\Delta C_{\text {hum }}\right| \times 100$ & $\left|\Delta C_{\text {pre }}\right| /\left|\Delta C_{\text {pre }}\right|+\left|\Delta C_{\text {hum }}\right| \times 100$ & $\begin{array}{l}\text { Climate change and } \\
\text { human activities jointly } \\
\text { increase fractional } \\
\text { vegetation cover and their } \\
\text { relative effects are the } \\
\text { percentage change in } \\
\text { cover }\end{array}$ \\
\hline & Scenario 2 & $>0$ & $<0$ & 100 & & $\begin{array}{c}\text { Climate change increases } \\
\text { fractional vegetation } \\
\text { cover }\end{array}$ \\
\hline & Scenario 3 & $<0$ & $>0$ & & 100 & $\begin{array}{c}\text { Human activities increase } \\
\text { fractional vegetation } \\
\text { cover }\end{array}$ \\
\hline \multirow[t]{3}{*}{$\begin{array}{l}\text { Vegetation } \\
\text { degradation } \\
\text { region }\end{array}$} & Scenario 1 & $<0$ & $<0$ & $\left|\Delta C_{\text {pre }}\right| /\left|\Delta C_{\text {pre }}\right|+\left|\Delta C_{\text {hum }}\right| \times 100$ & $\left|\Delta C_{\text {pre }}\right| /\left|\Delta C_{\text {pre }}\right|+\left|\Delta C_{\text {hum }}\right| \times 100$ & $\begin{array}{l}\text { Climate change and } \\
\text { human activities jointly } \\
\text { decrease fractional } \\
\text { vegetation cover and their } \\
\text { relative effects are the } \\
\text { percentage change in } \\
\text { cover }\end{array}$ \\
\hline & Scenario 2 & $<0$ & $>0$ & 100 & & $\begin{array}{c}\text { Climate change decreases } \\
\text { fractional vegetation } \\
\text { cover }\end{array}$ \\
\hline & Scenario 3 & $>0$ & $<0$ & & 100 & $\begin{array}{l}\text { Human activities } \\
\text { decrease fractional } \\
\text { vegetation cover }\end{array}$ \\
\hline
\end{tabular}

Note. $H_{\text {slope }}$ is the slope of the cover residual caused by human activities; $C_{\text {slope }}$ is the slope of the cover residual caused by climate change; $\Delta C_{\text {pre }}$ is the difference in the predicted cover caused by climate change at $t+i$ and $t ; \Delta C_{\text {hum }}$ is the difference in the predicted cover caused by human activities at $t+i$ and $t$.

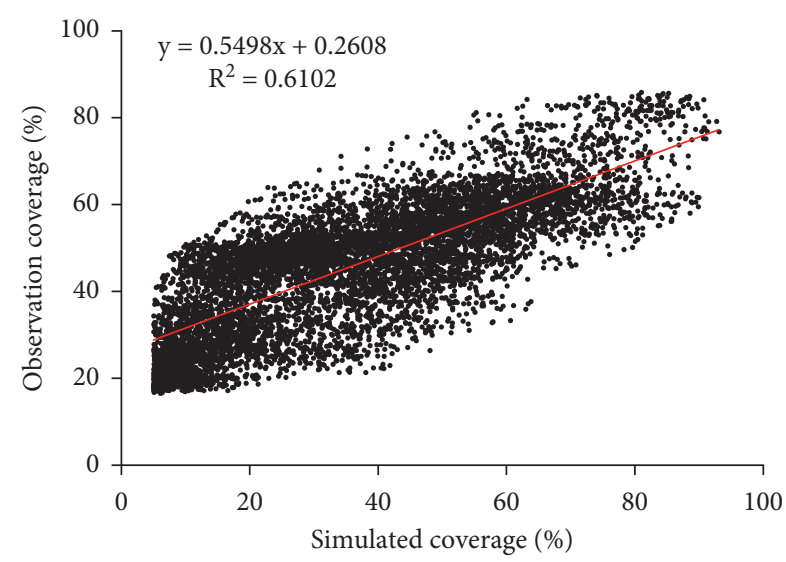

FIgURE 2: Validation of the dimidiate model simulation results.

The mean cover of the temperate meadow grassland region in the 10 -year period was $55.58 \%$, and this region mainly includes the Ulagae management region, northeastern part of the East Ujimqin Banner, the southeastern part of the West Ujimqin Banner, eastern Xilinhot, Duolun County, and Taibus Banner. The area of temperate meadow grassland accounted for $19.81 \%$ of the area of Xilingol grassland and mainly consists of Stipa baicalensis and bunch grasses. The mean cover of the temperate typical grassland region in the 10 -year period was $26.70 \%$ and this region mainly includes most parts of central Xilingol League. This grassland has the largest area, accounting for $61.07 \%$ of the area of Xilingol grassland and mainly consists of Stipa krylovii, Stipa grandis, Cleistogenes squarrosa, Aneurotepidimu chinense, Allium polyrhizum, and broad-leaved herbs. In addition, there are some desert plants, which mainly include Artemisia desertorum, Artemisia halodendron, Caragana microphylla, and Agropyron desertorum. These plants are mainly located at the Otindag Sandy Land. The mean cover of the temperate desert grassland region in the 10 -year period was $3.76 \%$ and this region mainly includes Erenhot, northwestern part of Sonid Left Banner, and the northwestern part of Sonid Right Banner and accounts for $19.12 \%$ of the area of Xilingol grassland. Major plant species include Stipa breviflora, Stipa tianschanica var. Gobica, Stipa glareosa, Cleistogenes songorica, and Allium polyrhizum. According to precipitation data statistics, it can be seen that the mean precipitation in the desert grassland in the 10-year period was $195.58 \mathrm{~mm}$.

\subsubsection{Annual Changes in Xilingol Grassland Cover and Their} Spatial Layout. The overall trend of Xilingol fractional vegetation cover in the 10-year period (2010-2019) showed fluctuating increase, with an increment rate of $2.21 \% / \mathrm{a}$. According to the variation trends of study site pixels in the 10 -year period (Figure 5), it can be seen that $24.92 \%$ of the region showed a decreasing trend, which is mainly located at 


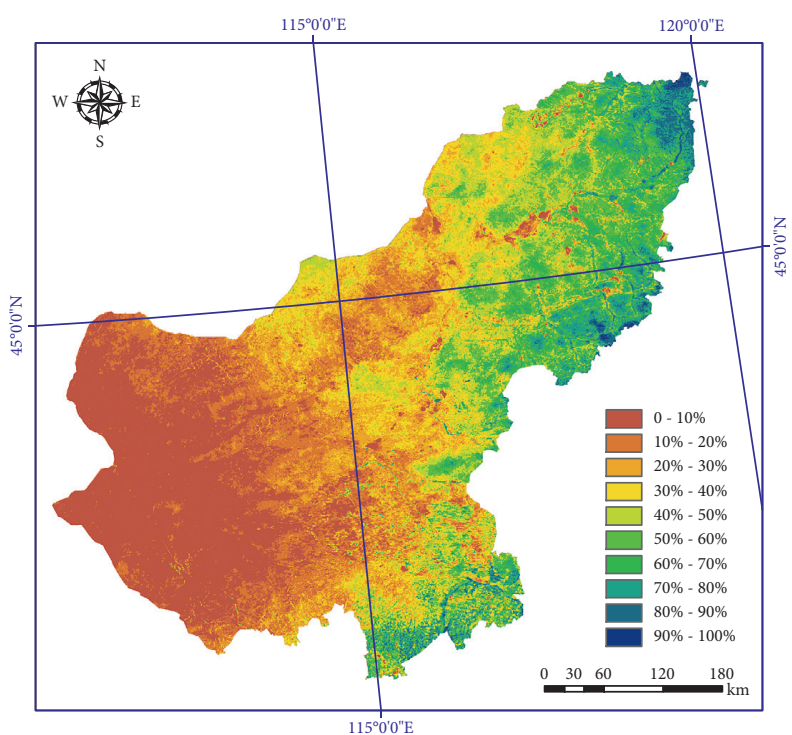

(a)

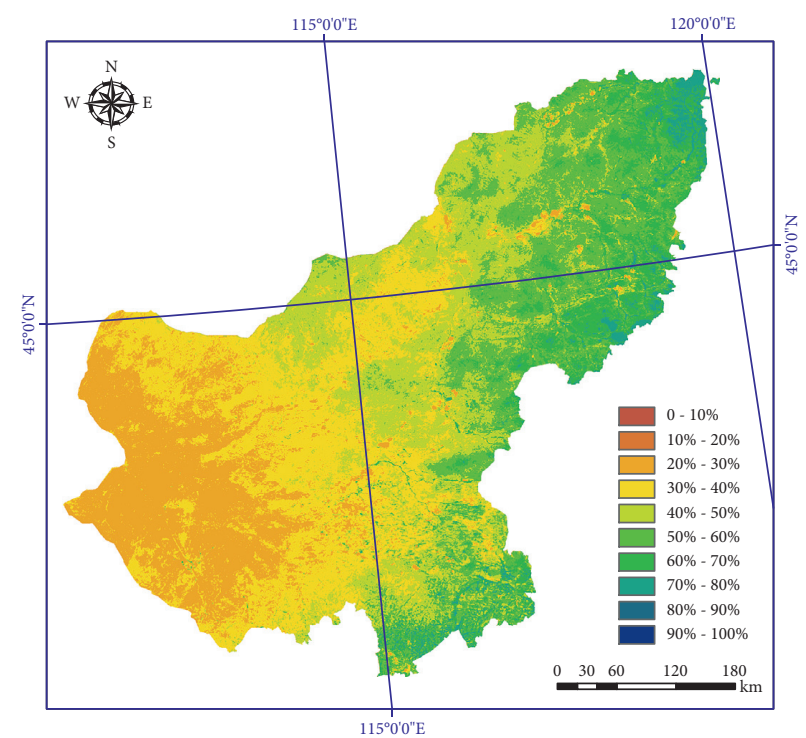

(b)

Figure 3: (a) Variation trends of dimidiate model estimation results and (b) fitted fractional vegetation cover.

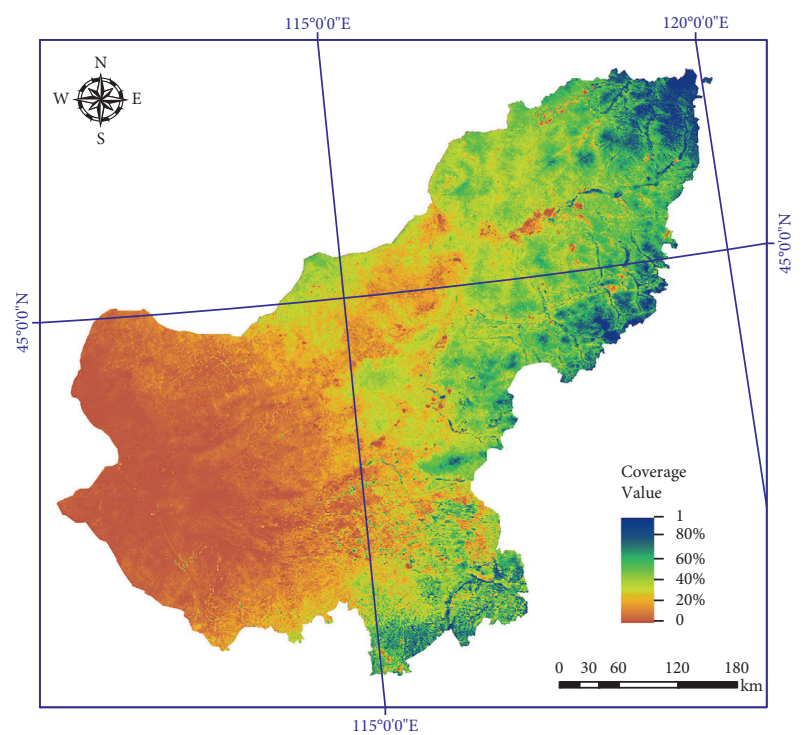

FIGURE 4: Spatial distribution map of mean fractional vegetation cover in 2010-2019.

the typical grassland region. Among these regions, the areas of regions with significant decrease $(0.05<P<0.1)$ and extremely significant decrease $(P<0.05)$ only accounted for $0.86 \%$ and $0.84 \%$ of the total area, respectively. Conversely, $75.08 \%$ of the region showed an increasing trend, of which the area of typical grassland was the highest (45.44\%), whereas desert grassland and meadow grassland accounted for $15.07 \%$ and $14.57 \%$, respectively. Among these regions, the regions with significant increase and extremely significant increase accounted for $9.54 \%$ and $6.00 \%$, respectively.

Based on the fluctuating increasing trend in fractional vegetation cover during the 10 -year period, we divided this period into three phases (Figure 6): The first phase was in 2010-2012. During this phase, fractional vegetation cover

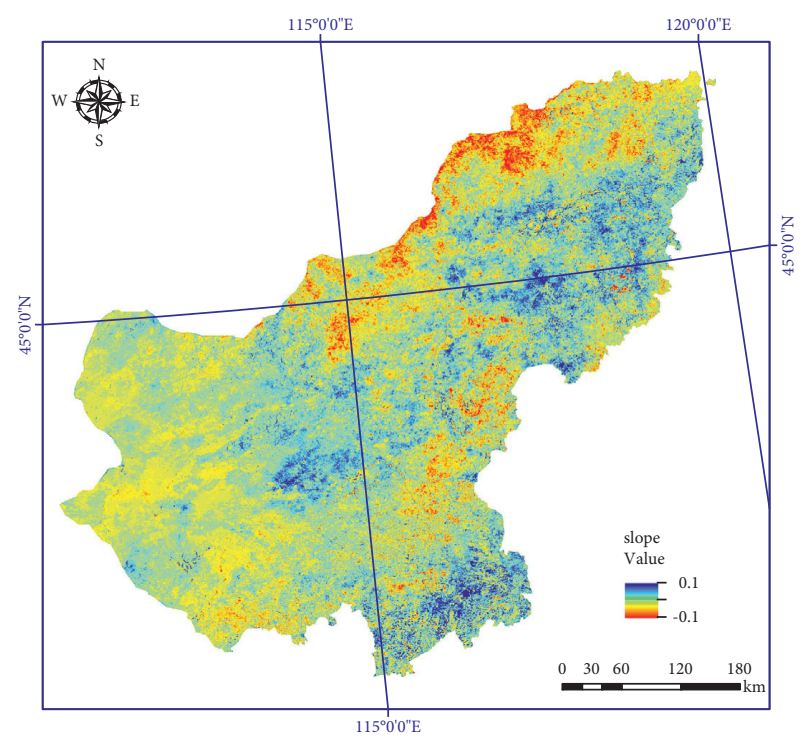

FIGURE 5: Slope distribution map of fractional vegetation cover changes in 2010-2019.

showed extremely significant increase, with an increment rate of $6.61 \% / \mathrm{a}$. The second phase was in 2012-2016. During this phase, fractional vegetation cover showed extremely significant decrease, with a reduction rate of $3.71 \% / \mathrm{a}$. The third phase was in 2016-2019. During this phase, fractional vegetation cover showed extremely significant increase again, with an increment rate of 5.21\%/a.

\subsection{Relationship between Fractional Vegetation Cover and Climate and Human Activities}

3.3.1. Spatial Layout of Precipitation and Temperature in Xilingol in a 10-Year Period. ANUSPLIN local thin-plate 


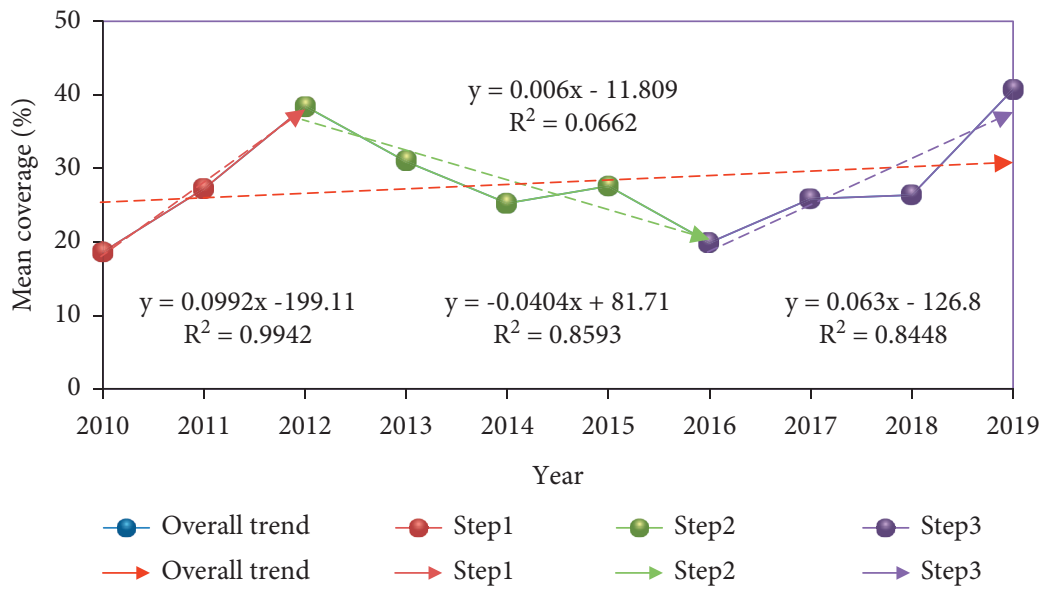

Figure 6: Variation trend graph of fractional vegetation cover in 2010-2019.

smoothing spline interpolation was used to obtain the 10 -year average temperature and precipitation spatial distribution map in Xilingol grassland (Figures 7(a) and 7(b)). The mean precipitation of the study site in the 10 -year period completely conforms to longitude zonal distribution patterns and sealand distribution pattern, with a decreasing trend from southeast to northwest. In addition, the distribution of grassland types and distribution of precipitation from high to low are completely consistent, which are meadow grasslands, typical grasslands, and desert grasslands in this order. This matches the classification criteria based on hydrothermal conditions in "China Grassland Resources." Mean precipitation in the 10-year period was $304.68 \mathrm{~mm}$, of which it was $403.01 \mathrm{~mm}, 306.74 \mathrm{~mm}$, and $195.58 \mathrm{~mm}$ in meadow grassland, typical grassland, and desert grassland, respectively. The distributions of mean temperature and precipitation in the study site in the 10-year period were basically opposites, showing a decreasing trend from southwest to northeast, which conforms to the latitude zonal distribution pattern. The 10 -year mean temperature was $3.03^{\circ} \mathrm{C}$, of which it was $1.99^{\circ} \mathrm{C}$, $2.92^{\circ} \mathrm{C}$, and $4.45^{\circ} \mathrm{C}$ in meadow grassland, typical grassland, and desert grassland, respectively.

From the statistical results (Figure 8), it can be seen that annual changes in precipitation and annual mean temperature in 2010-2019 both showed an increasing trend. However, precipitation is lower in years with high temperature and vice versa. For example, annual mean temperature in 2012 is the lowest in 10 years $\left(1.06^{\circ} \mathrm{C}\right)$ but annual precipitation was $389.94 \mathrm{~mm}$, which is the second highest precipitation in 10 years. In 2018, annual mean temperature is the highest in 10 years $\left(5.28^{\circ} \mathrm{C}\right)$ but annual precipitation is lower than the 10 -year mean. This phenomenon may be due to increased rainfall and reduced sunshine, leading to reduced temperature. In different types of grasslands, the variation trends of annual mean precipitation and annual mean temperature showed large differences (Figure 9). In the meadow grassland region, the 10-year mean precipitation fluctuated at 294.61$640.51 \mathrm{~mm}$, which showed a fluctuating increasing trend with an increment rate of $33.98 \mathrm{~mm} / 10$ a; mean temperature fluctuated at $0.32-4.30^{\circ} \mathrm{C}$ and increment rate was $0.13^{\circ} \mathrm{C} / 10$ a. In the typical grassland region, the 10 -year mean precipitation fluctuated at $217.94-640.51 \mathrm{~mm}$ and basically showed a fluctuating increasing trend with an increment rate of $32.23 \mathrm{~mm} / 10$ a, which is slightly lower than that in meadow grasslands; mean temperature fluctuated at $0.95-5.23^{\circ} \mathrm{C}$, and the increment rate was $0.13^{\circ} \mathrm{C} / 10 \mathrm{a}$, which is identical to meadow grassland. In the desert grassland, the 10-year mean precipitation fluctuated at $125.00-469.25 \mathrm{~mm}$ and basically showed a fluctuating increasing trend with an increment rate of $31.13 \mathrm{~mm} / 10 \mathrm{a}$, which is slightly lower than that in typical grasslands; mean temperature fluctuated at $2.18-6.45^{\circ} \mathrm{C}$, and increment rate was $0.11^{\circ} \mathrm{C} / 10 \mathrm{a}$, which is slightly lower than that in typical grasslands.

\subsubsection{Relationship between Fractional Vegetation Cover in} Xilingol and Climate. Pixel spatial analysis was used to analyze the partial correlation between fractional vegetation cover and temperature and precipitation using year as the unit. The partial correlation coefficients between fractional vegetation cover and annual precipitation and between fractional vegetation cover and annual mean temperature in various pixels in the study site in 2010-2019 were calculated. Results showed that, in the entire study site, the mean partial correlation coefficients between fractional vegetation cover and annual precipitation and annual mean temperature were 0.60 and -0.15 , respectively. The area of regions with positive correlation with annual precipitation accounted for $98.00 \%$ of total area, of which $12.18 \%$ and $65.01 \%$ of areas passed the $P<0.1$ and $P<0.05$ tests, respectively, and only $2.00 \%$ of regions showed negative correlation with annual precipitation (Figure 10(a)). The area of regions with positive correlation with annual mean temperature was $28.64 \%$, of which $1.62 \%$ and $1.39 \%$ of areas passed the $P<0.1$ and $P<0.05$ tests, respectively (Figure 10(b)). This shows that Xilingol fractional vegetation cover shows a higher correlation with precipitation. Liu et al. [18] and Wang et al. [19] pointed out that precipitation is the root cause affecting vegetation growth, which is consistent with the conclusion of this study. 


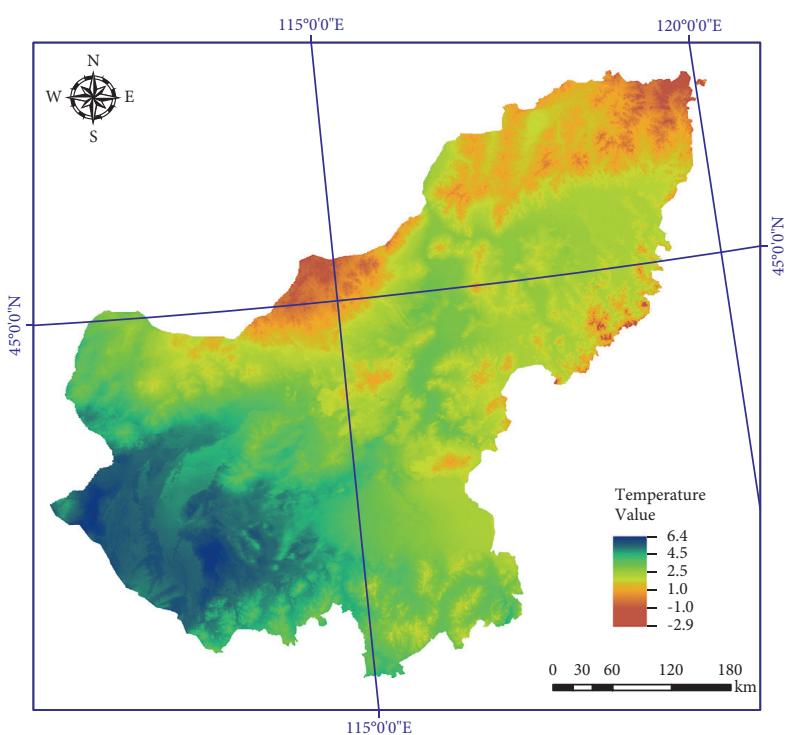

(a)

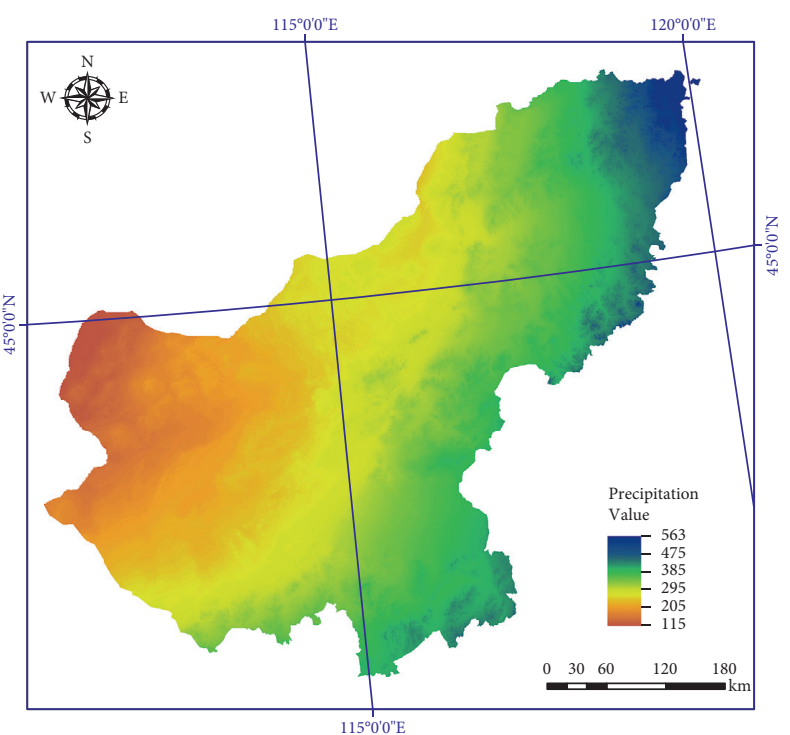

(b)

Figure 7: (a) Mean temperature and (b) precipitation distribution map in 2010-2019.

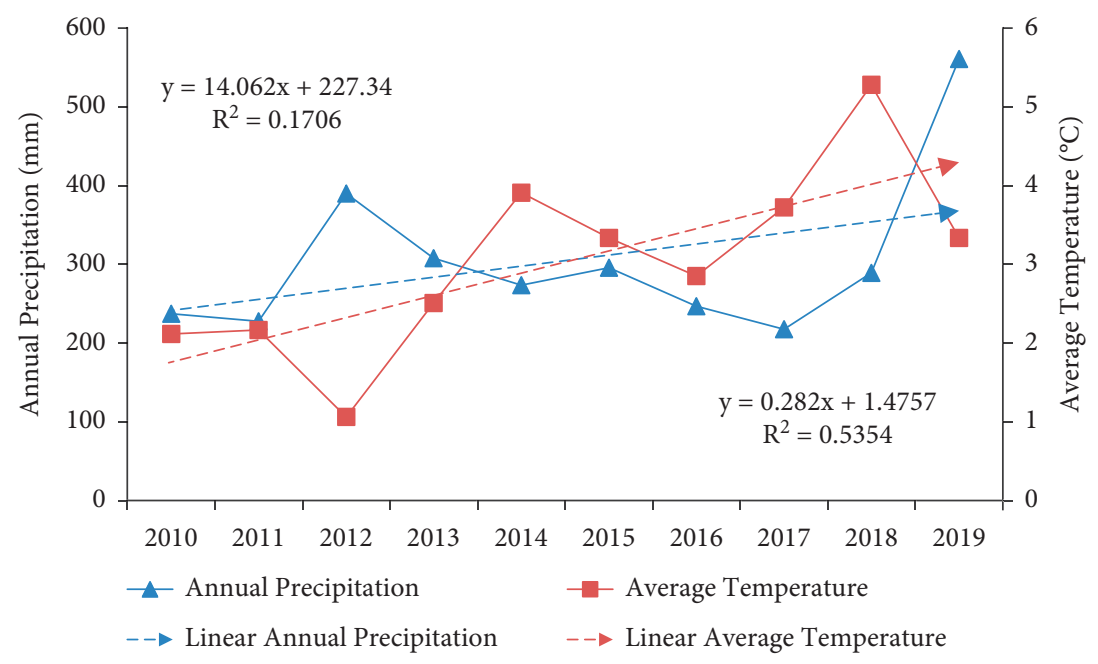

FIGURE 8: Variation trends of mean temperature and precipitation in 2010-2019.

The responses of vegetation growth towards precipitation and temperature in different regions show significant spatial differences. In the meadow grassland, the mean partial correlation coefficient between fractional vegetation cover and annual precipitation was 0.51 and regions with positive correlation accounted for $96.86 \%$ of the region area. The areas that passed the $P<0.1$ and $P<0.05$ tests accounted for $17.60 \%$ and $49.99 \%$ of the region area, respectively, showing that fractional vegetation cover shows extremely significant positive correlation with precipitation in meadow grasslands. Conversely, the mean partial correlation coefficient between fractional vegetation cover and annual mean temperature was 0.05 , and regions with positive correlation accounted for $55.03 \%$ of the region area. The areas that passed the $P<0.1$ and $P<0.05$ tests accounted for $0.98 \%$ and $0.84 \%$ of the region area, respectively, showing that fractional vegetation cover has a lower correlation with temperature in meadow grasslands. In the typical grassland, the mean partial correlation coefficient between fractional vegetation cover and annual precipitation was 0.60 and regions with positive correlation accounted for $97.97 \%$ of the region area. The areas that passed the $P<0.1$ and $P<0.05$ tests accounted for $12.46 \%$ and $65.87 \%$ of the region area, respectively, showing that vegetation growth in typical grasslands is more dependent on moisture compared to meadow grasslands. However, the mean partial correlation coefficient between fractional vegetation cover and annual mean temperature was -0.17 and regions with negative correlation accounted for $75.24 \%$ of the region area. The areas that passed the significance tests accounted for $13.50 \%$ of the region area, showing that fractional vegetation cover shows nonsignificant negative correlation with temperature 


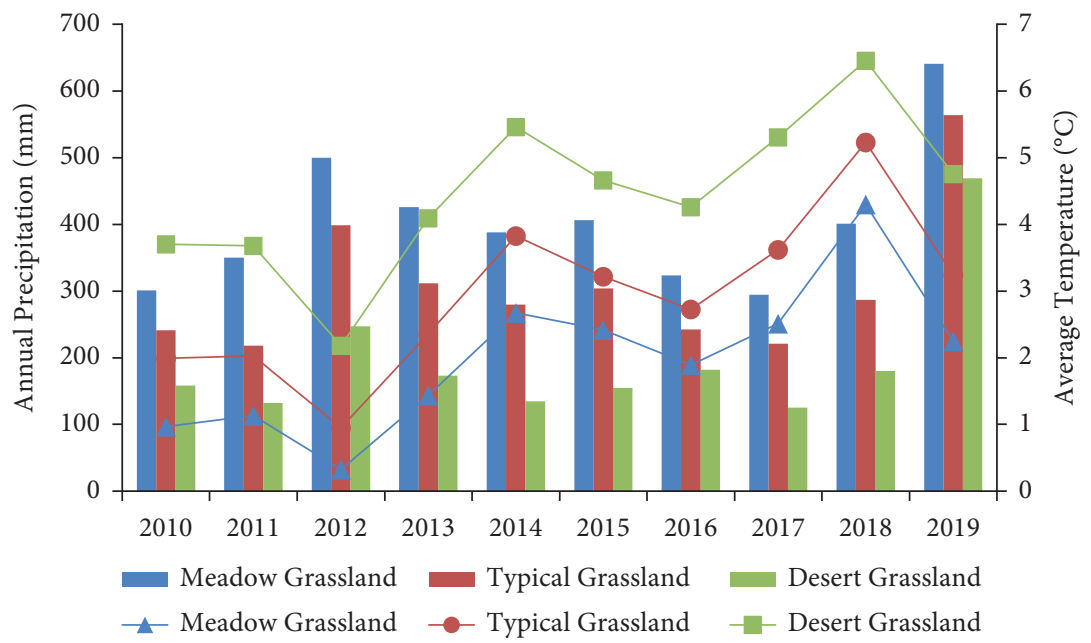

FigURE 9: Variation trends of mean temperature and precipitation in different types of grasslands in 2010-2019.

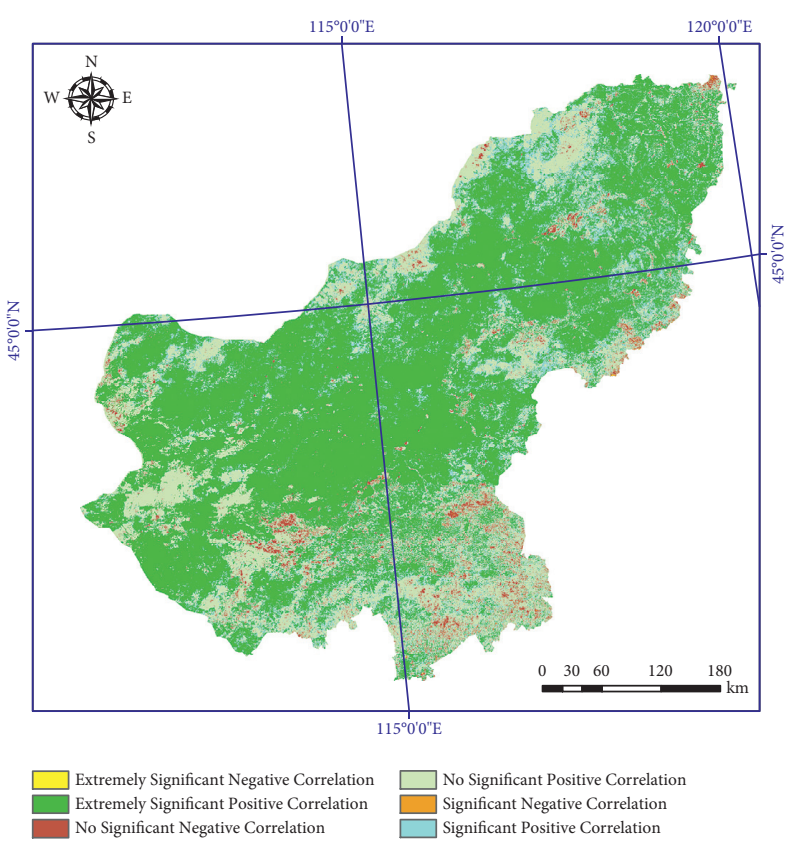

(a)

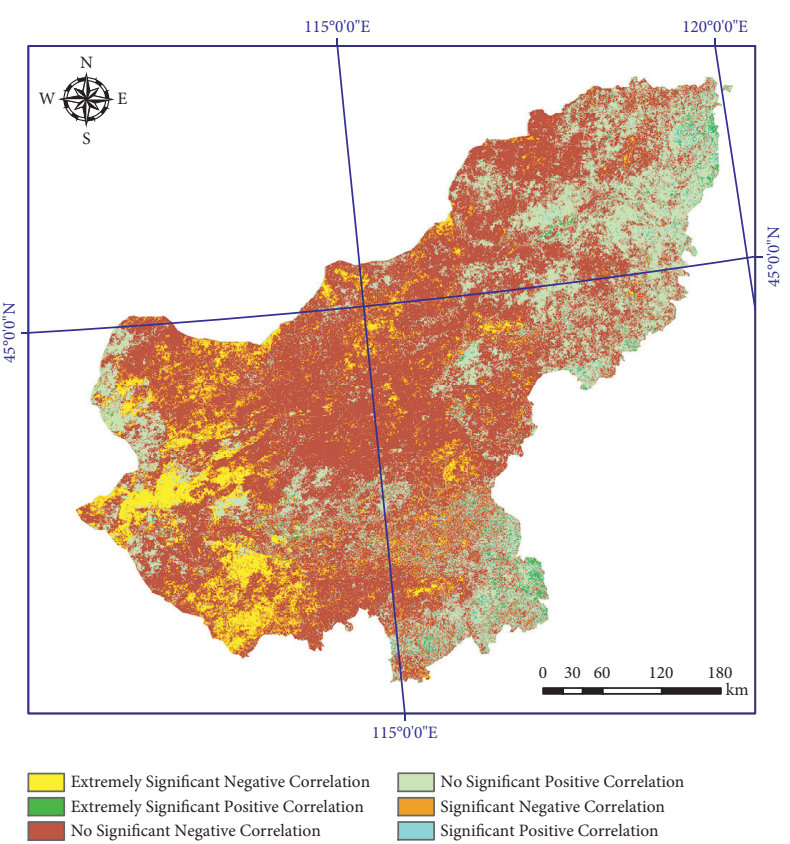

(b)

FIgURE 10: Correlation between fractional vegetation cover and (a) mean temperature and (b) mean precipitation in $2010-2019$.

in typical grasslands. In the desert grassland, the mean partial correlation coefficient between fractional vegetation cover and annual precipitation was 0.72 and regions with positive correlation accounted for $99.31 \%$ of the region area. The areas that passed the $P<0.1$ and $P<0.05$ tests accounted for $5.35 \%$ and $78.46 \%$ of the region area, respectively, showing that fractional vegetation cover is extremely dependent on moisture. The mean partial correlation coefficient between fractional vegetation cover and annual mean temperature was -0.31 and regions with positive correlation accounted for $87.09 \%$ of the region area. The areas that passed the $P<0.1$ and $P<0.05$ tests accounted for $12.25 \%$ and $18.89 \%$ of the region area, respectively, showing that fractional vegetation cover is negatively correlated with temperature in desert grasslands. This is mainly because the fractional vegetation cover in desert grassland is low, surface water storage capacity is weak, and increase in temperature will increase surface evapotranspiration and does not facilitate moisture absorption by vegetation. Yu et al. pointed out that high temperature will reduce available water for vegetation and affect vegetation growth and therefore show strong negative correlation [20], which is consistent with the conclusions of this study.

3.3.3. Relationship between Xilingol Fractional Vegetation Cover and Human Activities. From the annual changes in residual between actual and predicted fractional vegetation 
cover values in 2010-2019 and the spatial layout (Figure 11), there are large differences in spatial positions of the effects of human activities on vegetation. The area in which human activities promoted vegetation accounted for $44.41 \%$ and was mainly located at the eastern and southern parts of the study site. The vegetation area affected by human activities accounted for $55.59 \%$, which was mainly distributed in the west and north of the research site. The effects of human activities on vegetation also vary between the different types of grasslands (Figure 12). In meadow grasslands, the area in which human activities promoted vegetation accounted for $77.41 \%$ of the region area. In typical grasslands, the promoting effects of human activities on vegetation are weaker and occupy $44.43 \%$ of the region area. In desert grassland, vegetation growth is greatly inhibited by human activities and accounts for the largest area ratio among the three types of grassland $(89.98 \%)$.

\subsection{Analysis of the Relative Effects of Climate and Human} Activities on Fractional Vegetation Cover. Vegetation changes in the 10-year period were divided into improvement and degradation. Based on calculations on the variation trends of every pixel, it can be seen that degradation occurred in $33.09 \%$ of vegetation area in the study site, which mainly occurs in the western desert grassland, and contiguous patches were also present in the central typical grassland region. However, improvement occurred in $66.91 \%$ of vegetation area in the study site, which mainly occurs in most of the meadow grassland and large areas of typical grassland.

The three possible scenarios of the relative effects of climate change and human activities in vegetation degradation region or improvement region were used to calculate the relative effects of climate change and human activities on vegetation degradation regions or improvement regions in Xilingol in 2010-2019 (Figure 13). Overall, the regions in which the relative effects of climate change dominate in vegetation degradation regions accounted for $82.42 \%$ of the degradation region area, while regions in which the relative effect of human activities dominate accounted for $4.29 \%$ and regions in which both climate change and human activities resulted in vegetation degradation accounted for $13.28 \%$ of the area. From this, we can see that climate change is the main driver for vegetation degradation in the study site during the 10-year period. The regions in which the relative effects of climate change dominate in vegetation degradation regions accounted for $82.42 \%$ of the degradation region area, while regions in which the relative effects of human activities dominate accounted for $4.29 \%$ and regions in which both climate change and human activities resulted in vegetation degradation accounted for $13.28 \%$ of the area. The regions in which the relative effects of climate change dominate in vegetation improvement regions accounted for $37.24 \%$ of the degradation region area, while regions in which the relative effects of human activities dominate accounted for $27.79 \%$, and regions in which both climate change and human activities resulted in vegetation degradation accounted for $34.97 \%$ of the area. Hence, it can be seen that

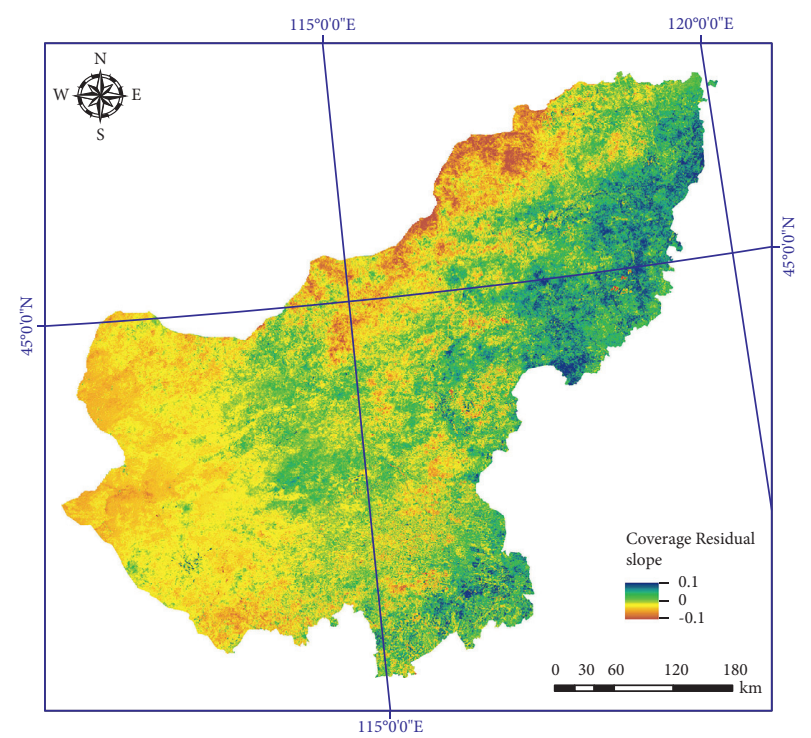

FIGURE 11: Slope distribution map of fractional vegetation cover residual changes in 2010-2019.

the joint effects of climate change and human activities in the 10 -year period promoted vegetation improvements in the study site.

\section{Discussion}

In recent years, NDVI has been widely used as a marker for characterization of vegetation growth in studies on vegetation changes. Researchers used NDVI to reflect vegetation growth to analyze the variation trends of vegetation. In this study, we introduced the fractional vegetation cover parameter and further converted NDVI to cover, which is often used to quantitatively describe the growth status and ecological status of vegetation and matches more with routine understanding of vegetation.

The dimidiate pixel model is the most commonly used model for estimating fractional vegetation cover among mixed pixel decomposition methods. The values inside fixed confidence intervals were used to substitute for pure pixel NDVI values to calculate the estimated fractional vegetation cover more precisely. However, the key is to select the maximum and minimum values for the confidence interval. The range of values used also differs between study sites; for example, $\mathrm{Ma}$ et al. [21] used a confidence interval of $0.5-99.5 \%$ in cumulative percentage in a study on fractional vegetation cover dynamics in Gannan grassland in China. $\mathrm{Li}$ et al. [22] used a confidence interval of 5-95\% in cumulative percentage in a study on the spatiotemporal evolution characteristics of fractional vegetation cover in the Jing-JingJi region in China. In this study, we selected a confidence interval of $5-90 \%$ in cumulative percentage to estimate fractional vegetation cover based on many years of research and accumulated experience on temperate grasslands in northern China. Validation by surface measurement data showed that estimation data has high correlation $(P<0.001)$ with a correlation coefficient of 0.7267 , showing that the confidence interval conforms to actual values. 


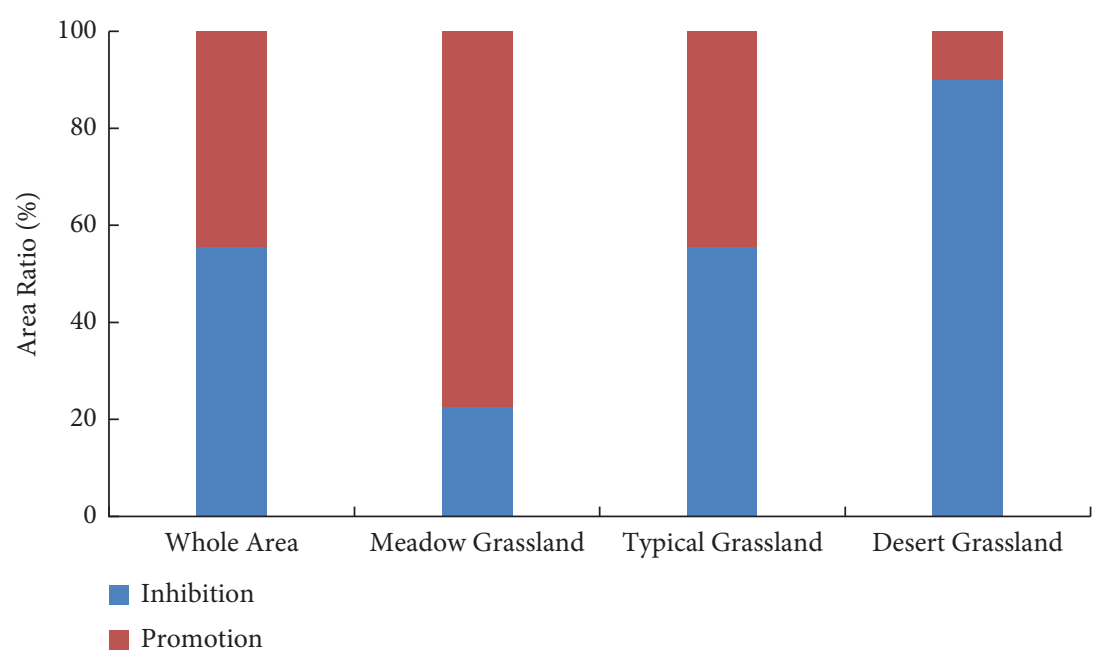

FIGURE 12: Effects of human activities on vegetation in different types of grassland in 2010-2019.

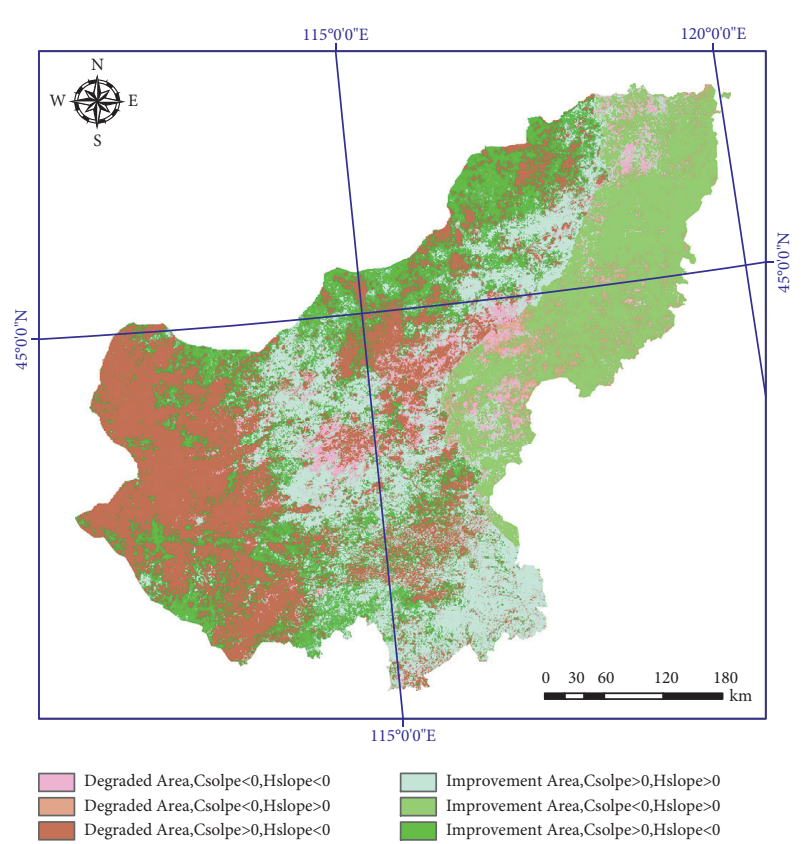

FIGURE 13: Relative effects of climate change and human activities on fractional vegetation cover in 2010-2019.

Previously, many researchers have examined the relationship between vegetation growth and climatic factors in Inner Mongolia. Miao et al. [23] used NDVI data in SPOT VEGETATION for inversion of fractional vegetation cover. They studied the relationship between fractional vegetation cover and climatic factors in temperate grassland in the Mongolian Plateau in a 50-year period and found that mean fractional vegetation cover in the growth phase has a strong positive correlation with precipitation during the same period, with a mean correlation coefficient of 0.610 . Sun et al. [24] used NDVI data in GIMMS to study the relationship between fractional vegetation cover and precipitation in Inner Mongolia in 1982-2000. They found that moisture is a limiting factor for vegetation growth in Inner Mongolia and the correlation coefficient between annual vegetation NDVI and precipitation is 0.64 . The annual fractional vegetation cover is extremely sensitive to annual precipitation, and the correlation coefficient is 0.60 in temperate grasslands in Inner Mongolia. Our results are in agreement with other previous studies. In addition, analyses on the correlation between fractional vegetation cover and climate are currently focused on temperature and precipitation. However, it is still insufficient to use these factors for research in the complex response relationship among vegetation, temperature, and precipitation. Climate change also includes other factors, for example, terrain, solar radiation, evapotranspiration, and carbon dioxide concentration [25], which together influence the vegetation coverage.

\section{Conclusion}

(1) Fractional vegetation cover in Xilingol decreases from the northeast to the southwest. The average vegetation coverage rate of the study sites was $28 \%$ during the ten years, and the average vegetation coverage rate was the highest in temperate meadow grassland, followed by typical temperate grassland, and temperate desert grassland was the lowest.

(2) The overall trend in Xilingol fractional vegetation cover in the 10-year period shows a fluctuating increasing trend, and regions with an increasing trend accounted for $75.08 \%$ of the study site, which are mainly located in the typical grassland region.

(3) The mean precipitation of the study site in the 10 -year period shows a decreasing trend from the southeast to the northwest, but mean temperature shows an opposite distribution pattern as it decreased from southwest to northeast. Changes in annual precipitation and annual mean temperature both show an increasing trend. However, precipitation is lower in years with high temperature and vice versa.

(4) Compared with temperature, annual precipitation has a higher correlation with fractional vegetation 
cover in the study site and is the main climatic factor that affects vegetation growth in the study site. In different types of grassland, desert grassland vegetation is more dependent on moisture, followed by typical grassland. In addition, desert grassland is also more sensitive to temperature.

(5) During the 10-year period in the study site, human activities have slightly greater inhibitory effects on vegetation growth than promoting effects. The growth of desert grassland vegetation is the largest influence by human activities in different grassland types.

(6) During the 10-year period in the study site, $33.09 \%$ and $66.91 \%$ of area underwent degradation and improvement, respectively. In vegetation degradation regions, climate change is the main factor promoting vegetation degradation. In vegetation improvement regions, human activities and climate change jointly promote vegetation improvement.

\section{Data Availability}

The data included in this paper are available without any restriction.

\section{Conflicts of Interest}

The authors declare that there are no conflicts of interest regarding the publication of this paper.

\section{Acknowledgments}

This work was funded by the National Natural Science Foundation of China Project "Study on Vegetation Stability under Seasonal Regulation of Grazing Intensity in Desert Steppe” (Grant no. NNSF- 31460126).

\section{References}

[1] A. A. Gitelson, Y. J. Kaufman, R. Stark, and D. Rundquist, "Novel algorithms for remote estimation of vegetation fraction," Remote Sensing of Environment, vol. 80, no. 1, pp. 76-87, 2002.

[2] Z. Gong, S. Zhao, and J. Gu, "Correlation analysis between vegetation coverage and climate drought conditions in North China during 2001-2013," Journal of Geographical Sciences, vol. 27, no. 2, pp. 143-160, 2017.

[3] Y. Yin, H. Liu, G. Liu, Q. Hao, and H. Wang, "Vegetation responses to mid-Holocene extreme drought events and subsequent long-term drought on the southeastern Inner Mongolian Plateau, China," Agricultural and Forest Meteorology, vol. 178-179, pp. 3-9, 2013.

[4] G. Gutman and A. Ignatov, "The derivation of the green vegetation fraction from NOAA/AVHRR data for use in numerical weather prediction models," International Journal of Remote Sensing, vol. 19, no. 8, pp. 1533-1543, 1998.

[5] T. Hilker, A. I. Lyapustin, C. J. Tucker et al., "Vegetation dynamics and rainfall sensitivity of the Amazon," Proceedings of the National Academy of Sciences, vol. 111, no. 45, pp. 16041-16046, 2014.
[6] X. Zhao, K. Tan, S. Zhao, and J. Fang, "Changing climate affects vegetation growth in the arid region of the northwestern China," Journal of Arid Environments, vol. 75, no. 10, pp. 946-952, 2011.

[7] F. Peng, W. J. Fan, X. R. Xu, and X. Liu, "Analysis on temporal-spatial change of vegetation coverage in Hulunbuir steppe (2000-2014)," Acta Scientiraum Naturalium Universitatis Pekinensis, vol. 53, no. 3, pp. 563-572, 2017, In Chinaese.

[8] K. J. Wessels, S. D. Prince, J. Malherbe, J. Small, P. E. Frost, and D. Vanzyl, "Can human-induced land degradation be distinguished from the effects of rainfall variability? A case study in South Africa," Journal of Arid Environments, vol. 68, no. 2, pp. 271-297, 2007.

[9] Y. C. Xie and Z. Y. Sha, "Quantitative analysis of driving factors of grassland degradation: a case study in Xilin River basin, Inner Mongolia," Science World Journal, vol. 1-14, 2012.

[10] B. Sun, Z. Li, Z. Gao et al., "Grassland degradation and restoration monitoring and driving forces analysis based on long time-series remote sensing data in Xilin Gol League," Acta Ecologica Sinica, vol. 37, no. 4, pp. 219-228, 2017.

[11] M. F. Hutchinson and T. B. Xu, ANUSPLIN version4.4 User Guide, Fenner School of Environment and Society, Australia National University, Canberra, Australia, 2013.

[12] J. Qi, R. C. Marsett, M. S. Moran, D. C. Goodrich, and X. X. Zhang, "Spatial and temporal dynamics of vegetation in the San Pedro River basin area," Agricultural and Forest Meteorology, vol. 105, no. 1-3, pp. 55-68, 2000.

[13] S. Barati, B. Rayegani, M. Saati, A. Sharifi, and M. Nasri, "Comparison the accuracies of different spectral indices for estimation of vegetation cover fraction in sparse vegetated areas," The Egyptian Journal of Remote Sensing and Space Science, vol. 14, no. 1, pp. 49-56, 2011.

[14] F. Li, W. Chen, Y. Zeng, Q. Zhao, and B. Wu, "Improving estimates of grassland fractional vegetation cover based on a pixel dichotomy model: a case study in inner Mongolia, China," Remote Sensing, vol. 6, no. 6, pp. 4705-4722, 2014.

[15] S. J. Mu, J. Li, Y. Chen, C. Gang, and W. Ju, "Spatial differences of variations of vegetation coverage in Inner Mongolia during 2001-2010," Acta Geographica Sinica, vol. 67, no. 9, pp. 1255-1268, 2012, In Chinaese.

[16] J. Evans and R. Geerken, "Discrimination between climate and human-induced dryland degradation," Journal of Arid Environments, vol. 57, no. 4, pp. 535-554, 2004.

[17] D. Y. Xu, X. W. Kang, Z. L. Liu, D. F. Zhuang, and J. J. Pan, "Study on the relative role of climate change and human activities in desertification process in Erdos Region," Science in China, Series A D, vol. 39, no. 4, pp. 516-528, 2009, In Chinaese.

[18] Y. Liu, Y. Li, S. Li, and S. Motesharrei, "Spatial and temporal patterns of global NDVI trends: correlations with climate and human factors," Remote Sensing, vol. 7, no. 10, pp. 13233-13250, 2015.

[19] J. Wang, P. M. Rich, and K. P. Price, “Temporal responses of NDVI to precipitation and temperature in the central Great Plains, USA," International Journal of Remote Sensing, vol. 24, no. 11, pp. 2345-2364, 2003.

[20] M. Yu, G. L. Wang, and J. S. Pal, "Effects of vegetation feedback on future climate change over West Africa," Climate Dynamics, vol. 46, pp. 1-20, 2015.

[21] Y. L. Ma, X. Cui, Q. S. Feng, and T. G. Liang, "Dynamic changes of grassland vegetation coverage from 2001 to 2011 in Gannan Prefecture," Acta Prataculturae Siniva, vol. 23, no. 4, pp. 1-9, 2014, In Chinaese. 
[22] Y. H. Li, J. H. Teng, and W. T. Ma, “Temporal and spatial evolution characteristics of vegetation coverage in BeijingTianjin-Hebei Region," Bulletin of Surveying and Mapping, vol. 33, no. 11, pp. 1302-1307, 2019, In Chinaese.

[23] L. J. Miao, C. Jiang, H. Bin, L. Qiang, F. Zhu, and X. Cui, "Response of vegetation coverage to climate change in Mongolian Plateau during recent 10 years," Acta Ecologica Sinica, vol. 34, no. 5, pp. 1295-1301, 2014, In Chinaese.

[24] Y. L. Sun, P. Guo, X. D. Yan, and T. B. Zhao, "Dynamics of vegetation cover and its relationship with climate change and human activities in Inner Mongolia," Journal of Natural Resources, vol. 25, no. 3, pp. 407-414, 2010, In Chinaese.

[25] S. Piao, G. Yin, J. Tan et al., "Detection and attribution of vegetation greening trend in China over the last 30 years," Global Change Biology, vol. 21, no. 4, pp. 1601-1609, 2015. 